\title{
Generalized Fuzzy Data Mining for Incomplete Information
}

\author{
Poli Venkata Subba Reddy \\ Department of Computer Science and Engineering, Sri Venkateswara University, Tirupati, India \\ Email: pvsreddy@hotmail.co.in
}

How to cite this paper: Reddy, P.V.S. (2018) Generalized Fuzzy Data Mining for Incomplete Information. Journal of Software Engineering and Applications, 11, 285-298.

https://doi.org/10.4236/jsea.2018.116018

Received: March 1, 2018

Accepted: June 10, 2018

Published: June 13, 2018

Copyright $\odot 2018$ by author and Scientific Research Publishing Inc. This work is licensed under the Creative Commons Attribution International License (CC BY 4.0).

http://creativecommons.org/licenses/by/4.0/

\section{(c) (i) Open Access}

\begin{abstract}
Defining data with fuzziness made the knowledge discovery process easy and secure to data in data mining. The fuzzy data bases may have linguistic variables. In this paper, fuzzy conditional inference and reasoning are studied for generalized fuzzy data mining. Generalized fuzzy data mining and reasoning is studied with two membership functions "Belief" and "Disbelief". The fuzzy logic with two membership functions will give more evidence than single membership function. The fuzzy certainty factor is studied as difference between these functions and made it as single membership function. The fuzzy data mining methods are studied. The generalized data mining is studied with different fuzzy conditional inferences. The business intelligence is given as an example.
\end{abstract}

\section{Keywords}

Fuzzy Logic, Generalized Fuzzy Logic, Fuzzy Certainty Factor, Business Intelligence

\section{Introduction}

Zadeh [1] defined fuzzy set with single membership function. Zadeh [2], Mamdani [3] and TSK [4] proposed fuzzy conditional inference. The main objective of fuzzy data mining is knowledge discovery process. The reasoning may be considered as one of the data mining technique during knowledge discovery process. The data mining with fuzzy databases will reduce the time and make easy to access for Big Data analysis. The fuzzy data mining may be dealt with linguistic variables. The generalized fuzzy data mining with two membership function will give more evidence. The fuzzy data mining and fuzzy reasoning made the knowledge discovery process easy through the overall observation and reasoning. The two membership functions shall be made as single fuzzy mem- 
bership function with fuzzy certainty factor. The fuzzy certainty factor will give single membership as difference between two membership functions.

In the following, fuzzy conditional inference and reasoning are studied. Generalized fuzzy logic is discussed. The fuzzy certainty factor is studied as single membership function. The generalized fuzzy data mining and reasoning are studied.

\section{Fuzzy Logic}

Various theories are studied to deal with imprecise, inconsistent and inexact information and these theories deal with likelihood (probability) where as fuzzy logic with mind (commonsense). Zadeh [1] has introduced fuzzy set as a model to deal with incomplete information as single membership functions. The fuzzy set is a class of objects with a continuum of grades of membership. The set $A$ of $X$ is characterized by its membership function $\mu_{A}(x)$ and ranging values in the unit interval $[0,1]$

$$
\mu_{A}(x): X \rightarrow[0,1], x \in X \text { where " }+ \text { " is union }
$$

For example, the fuzzy proposition " $\mathrm{x}$ is demand"

$$
\begin{gathered}
\text { demand }=0.4 / x_{1}+0.5 / x_{2}+0.6 / x_{3}+0.8 / x_{4}+0.9 / x_{5} \\
\text { not demand }=0.6 / x_{1}+0.5 / x_{2}+0.4 / x_{3}+0.2 / x_{4}+0.1 / x_{5}
\end{gathered}
$$

For instance "Item 1 has demand" and the fuzziness of "demand" is 0.8 .

The Graphical representation of "demand" and "not demand" is shown in Figure 1.

The fuzzy logic is defined as combination of fuzzy sets using logical operators [1]. Some of the logical operations are given below.

Let $A, B$ and $C$ be fuzzy sets. The operations on fuzzy sets are given bellow.

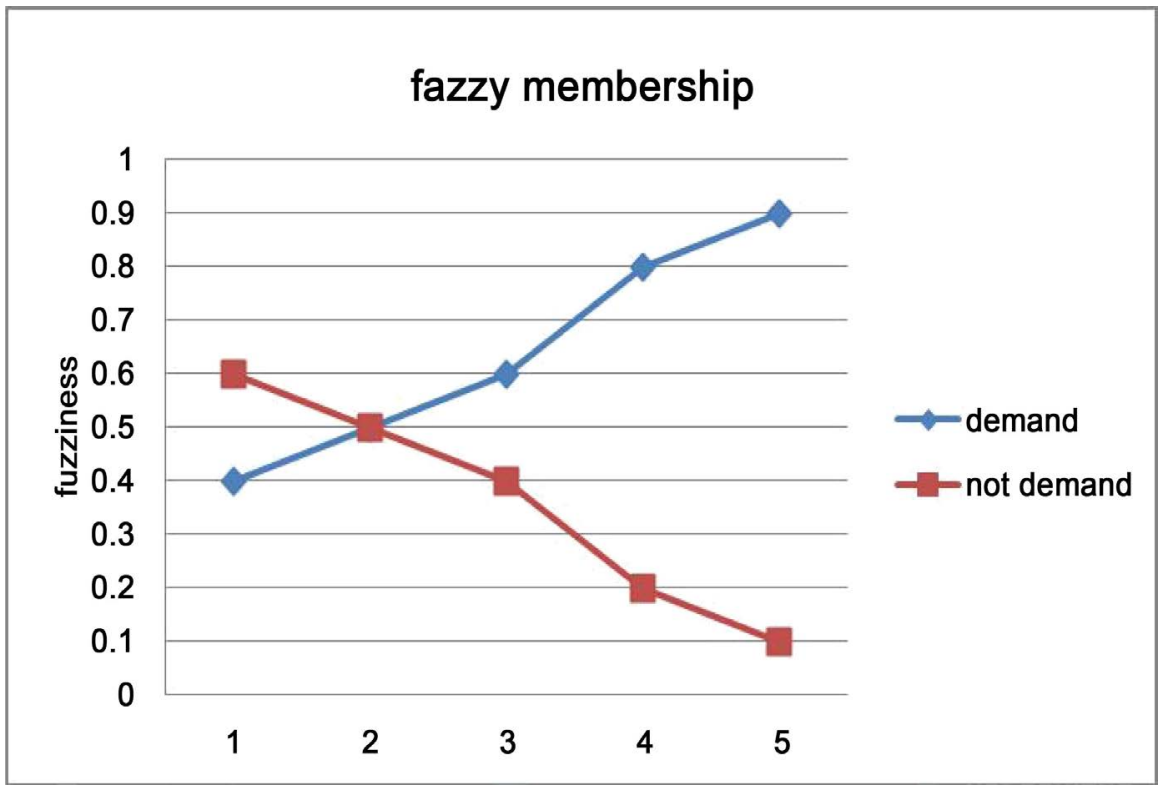

Figure 1. Fuzzy membership function. 


\section{Negation}

$X$ is not $A$

$$
A^{\prime}=1-\mu_{A}(x) / x
$$

\section{Conjunction}

$x$ is $A$ and $y$ is $B \rightarrow(x, y)$ is $A \Lambda B$

$$
A \Lambda B=\min \left\{\mu_{A}(x), \mu_{B}(y)\right\} /(x, x)
$$

\section{Disjunction}

$x$ is $A$ and $x$ is $B \rightarrow(\mathrm{x}, \mathrm{x})$ is $A V B$

$$
A V B=\max \left\{\mu_{A}(x), \mu_{B}(y)\right\} /(x, x)
$$

\section{Composition}

$$
\text { Ao } R=\min \left\{\mu_{A}(x), \mu_{R}(x, y)\right\} / x
$$

The fuzzy propositions may contain quantifiers like "very", "more or Less". These fuzzy quantifiers may be eliminated as

\section{Concentration}

$x$ is very $A$

$$
\mu_{\mathrm{very} A}(x)=\mu_{A}(x)^{2}
$$

\section{Diffusion}

$x$ is very $A$

$$
\mu_{\text {more or less } A}(x)=\mu_{A}(x)^{0.5}
$$

The fuzzy reasoning [2] is a drawing conclusion from fuzzy propositions using fuzzy inference rules.

Some of the fuzzy reasoning rules are given below.

$\mathrm{R} 1: x$ is $A$

$x$ and $y$ are $B$

$y$ is $A \Lambda B$

R2: $x$ is $A$

$x$ or $y$ are $B$

$y$ is $A V B$

R3: $x$ and $y$ are $A$

$y$ and $z$ are $B$

$y$ and $z$ are $\mathrm{A} \circ B$

R4: $x$ is $A_{1}$

if $x$ is $A$ then $y$ is $B$

$y$ is $A_{1}$ o $(A \rightarrow B)$ 


\section{Fuzzy Conditional Inference}

Zadeh [2] fuzzy conditional inference is given by if $x$ is $A$ then $y$ is $B$

$$
A \rightarrow B=\min \left\{1,1-\mu_{A}(x)+\mu_{B}(x)\right\} / x
$$

if $x$ is $A$ and $x$ is $B$ then $x$ is $C$

$$
=\min \left\{1,1-\left(\mu_{A}(x)+\mu_{B}(x)\right)+\mu_{C}(x)\right\} / x
$$

Mamdani [3] fuzzy conditional inference is given by

$$
A \rightarrow B=\min \left\{\mu_{A}(x), \mu_{B}(x)\right\} / x
$$

if $x$ is $A$ and $x$ is $B$ then $x$ is $C$

$$
=\min \left\{\left(\mu_{A}(x), \mu_{B}(x)\right), \mu_{C}(x)\right\} / x
$$

TSK [4] fuzzy conditional inference is given by

if $x$ is $A$ then $y=f(x)$ is $B$

if $x_{1}$ is $A_{1}$ and $x_{2}$ is $A_{2}$ and $\ldots$ and $x_{n}$ is $A_{n}$ then $y$ is $B$ where $y=f\left(x_{1}, x_{2}, \cdots, x_{n}\right)$.

The proposed fuzzy conditional inference using TSK is given by

The additive mapping $f: R \rightarrow R$ is called derivation if

$$
f(x+y)=f(x)+f(y)
$$

t-norm is used in several fuzzy classification system

$$
\begin{aligned}
& t(x+y) \leq \max (t(x), t(y)) \\
& t(x * y) \leq \min (t(x), t(y))
\end{aligned}
$$

Substitute fuzzy sets $A_{1}$ and $A_{2}$ instead of $x$ and $y$

$$
\begin{aligned}
& t\left(A_{1}+A_{2}\right) \leq \max \left\{\left(t\left(A_{1}\right), t\left(A_{2}\right)\right\}\right. \\
& t\left(A_{1} * A_{2}\right) \leq \min \left\{t\left(A_{1}\right), t\left(A_{2}\right)\right\}
\end{aligned}
$$

The fuzzy conditional inference is given by

if $x_{1}$ is $A_{1}$ and $x_{2}$ is $A_{2}$ and $\ldots$ and $x_{n}$ is $A_{n}$ then $B=t\left(A_{1}, A_{2} \cdots, A_{n}\right)$ where

$$
\begin{gathered}
A_{1}+A_{2}=A_{1} V A_{2}, \\
A_{1} * A_{2}=A_{1} \Lambda A_{2} \\
B=t\left(A_{1}, A_{2}, \cdots, A_{n}\right)=\min \left(A_{1}, A_{2}, \cdots, A_{n}\right) \\
B=\min \left(A_{1}, A_{2}, \cdots, A_{n}\right)
\end{gathered}
$$

Here is the "Consequent part" is given from "Precedent part" of the fuzzy rule.

Using Mamdani fuzzy conditional inference, the proposed fuzzy conditional inference is given by

if $x_{1}$ is $A_{1}$ and $x_{2}$ is $A_{2} \ldots$ and $x_{n}$ is $A_{n}$ then $y$ is $B$ 


$$
\begin{gathered}
=\min \left\{\min \left(A_{1}, A_{2}, \cdots, A_{n}\right), B\right\} \\
=\min \left(A_{1}, A_{2}, \cdots, A_{n}\right)
\end{gathered}
$$

where $B=\min \left(A_{1}, A_{2}, \cdots, A_{n}\right)$.

Proposed fuzzy conditional inference give by if $x$ is $A$ then $y$ is $B$

$$
\begin{gathered}
=\min \left(\mu_{A}(x), \mu_{B}(y)\right) \\
=\min \left(\mu_{A}(x), \mu_{A}(x)\right)=\left\{\mu_{A}(x)\right\}
\end{gathered}
$$

Here is the fuzzy conditional inference is given for fuzzy rule.

The Mamdani [3] nested fuzzy conditional inference "if $x$ is $A$ then if $y$ is $B$ then $z$ is $C^{\prime}$ is given by

$$
\begin{aligned}
& A \rightarrow(B \rightarrow C)=\min \left\{\mu_{A}(x), \min \left(\mu_{B}(y), \mu_{C}(z)\right)\right\} \\
& =\min \left\{\mu_{A}(x), \min \left(\mu_{B}(y), \mu_{C}(z)\right)\right\}
\end{aligned}
$$

if $x$ is $A$ then if $y$ is $B$ then $z$ is $C$ is equivalent to

if $x$ is $A$ and $y$ is $B$ then $z$ is $C$

The proposed nested fuzzy conditional inference "if $x$ is $A$ then if $y$ is $B$ then $z$ is $C^{\prime}$ is given by

$$
\begin{aligned}
& A \rightarrow(B \rightarrow C)=\min \left\{\mu_{A}(x), \min \left(\mu_{B}(y)\right)\right\} \\
& =\min \left\{\mu_{A}(x), \min \left(\mu_{B}(y)\right)\right\}=\mu_{A}(x)
\end{aligned}
$$

The advantages of proposed fuzzy conditional inferences are:

It gives inference for consequent part;

It gives different fuzzy conational inference for fuzzy rule;

It gives different fuzzy conditional inference for nested fuzzy rule.

\section{Fuzzy Certainty Factor}

Zadeh [1] defined fuzzy set with single membership function. The generalized fuzzy logic is defending by two fold fuzzy set [5]. The two fold fuzzy set is a fuzzy set with two membership functions "belief" and "disbelief".

The generalized fuzzy set simply as two fold fuzzy set and is defined by

$$
A=\left\{\mu_{A}^{\text {belief }}(x), \mu_{A}^{\text {disbelief }}(x)\right\}
$$

In MYCIN [6], the CF[h,e] is defined with $\mathrm{MB}[\mathrm{h}, \mathrm{e}]$ and $\mathrm{MD}[\mathrm{h}, \mathrm{e}]$, where "e" is evidence and " $h$ " is hypothesis and CF, MB and MD are probabilities.

The fuzzy certainty factor (FCF) is defined with fuzziness instead of probability.

$$
\mu_{A}^{\mathrm{FCF}}(x)=\mu_{A}^{\text {belief }}(x)-\mu_{A}^{\text {disbelief }}(x)
$$

The above are interpreted as redundant, insufficient and sufficient information respectively. 
The FCF is a single membership function. The fuzzy logic and reasoning of FCF is applicable similar to the fuzzy logic with single membership function.

For instance

$$
\begin{aligned}
\text { demand }= & \left\{0.4 / x_{1}+0.5 / x_{2}+0.6 / x_{3}+0.8 / x_{4}+0.9 / x_{5},\right. \\
& \left.0.05 / x_{1}+0.1 / x_{2}+0.15 / x_{3}+0.2 / x_{4}+0.25 / x_{5}\right\} \\
= & 0.35 / x_{1}+0.4 / x_{2}+0.45 / x_{3}+0.6 / x_{4}+0.65 / x_{5}
\end{aligned}
$$

The graphical representation of FCF is shown in Figure 2.

\section{Application to Fuzzy Conditional Inference}

The business intelligence is needed to deal with incomplete information. Fuzzy logic deals with incomplete information. The proposed fuzzy conditional inference [7] is discussed for business intelligence.

The business intelligence needs commonsense. The fuzzy logic deals incomplete information with commonsense.

Consider Business fuzzy rule

If $x$ is demand of the product then $x$ is Price

Let $x_{1}, x_{2}, x_{3}, x_{4}, x_{5}$ be the Items.

Consider Generalized fuzzy set

$$
\begin{aligned}
& \text { demand }=\left\{0.3 / x_{1}+0.4 / x_{2}+0.5 / x_{3}+0.7 / x_{4}+0.8 / x_{5},\right. \\
& \left.0 / x_{1}+0 / x_{2}+0.5 / x_{3}+1 / x_{4}+1 / x_{5}\right\} \\
& \mu_{\text {demand }}^{\mathrm{FCF}}(x)=0.3 / x_{1}+0.4 / x_{2}+0.45 / x_{3}+0.6 / x_{4}+0.7 / x_{5} \\
& \text { price }=\left\{0.4 / x_{1}+0.5 / x_{2}+0.6 / x_{3}+0.8 / x_{4}+0.9 / x_{5},\right. \\
& \left.0 / x_{1}+0 / x_{2}+0 / x_{3}+1 / x_{4}+1 / x_{5}\right\} \\
& \mu_{\text {price }}^{\mathrm{FCF}}(x)=0.4 / x_{1}+0.5 / x_{2}+6 / x_{3}+0.7 / x_{4}+0.8 / x_{5}
\end{aligned}
$$

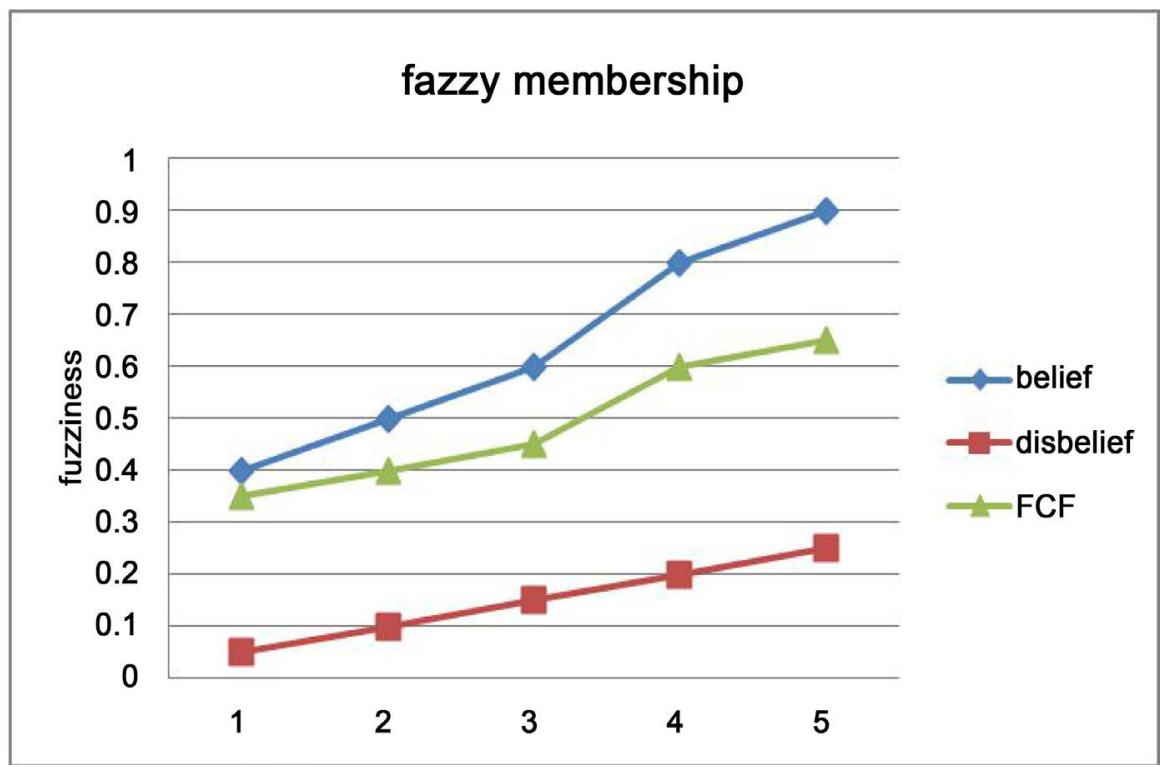

Figure 2. Fuzzy certainty factor. 
Zadeh [1] [2] inference is given by

$$
\begin{gathered}
A \rightarrow B=\min \left\{1,1-\mu_{A}(x)+\mu_{B}(x)\right\} \\
\mu_{\text {demand } \rightarrow \text { Price }}^{\mathrm{FCF}}(x)=1.0 / x_{1}+1.0 / x_{2}+1.0 / x_{3}+1.0 / x_{4}+1.0 / x_{5}
\end{gathered}
$$

Mamdani [3] inference is given by

$$
\begin{gathered}
A \rightarrow B=\min \left\{\mu_{A}(x), \mu_{B}(x)\right\} \\
\mu_{\text {demand } \rightarrow \text { Price }}^{\mathrm{FCF}}(x)=0.3 / x_{1}+0.4 / x_{2}+0.45 / x_{3}+0.6 / x_{4}+0.7 / x_{5}
\end{gathered}
$$

Proposed inference is given by

$$
\begin{gathered}
A \rightarrow B=\left\{\mu_{A}(x)\right\} \\
\mu_{\text {demand } \rightarrow \text { Price }}^{\mathrm{FCF}}(x)=0.3 / x_{1}+0.4 / x_{2}+0.45 / x_{3}+0.6 / x_{4}+0.7 / x_{5}
\end{gathered}
$$

very small demand $=\left\{0.09 / x_{1}+0.16 / x_{2}+0.20 / x_{3}+0.36 / x_{4}+0.49 / x_{5}\right\}$

Zadeh [2] fuzzy reasoning is given by

$$
\begin{aligned}
& \text { very small demand } o \text { demand } \rightarrow \text { price } \\
&=\left\{0.09 / x_{1}+0.16 / x_{2}+0.20 / x_{3}+0.36 / x_{4}+0.49 / x_{5}\right\} \\
& o\left\{1.0 / x_{1}+1.0 / x_{2}+1.0 / x_{3}+1.0 / x_{4}+1.0 / x_{5}\right\} \\
&=\left\{0.09 / x_{1}+0.16 / x_{2}+0.20 / x_{3}+0.36 / x_{4}+0.49 / x_{5}\right\}
\end{aligned}
$$

Mamdani [3] fuzzy reasoning is given by

$$
\begin{aligned}
& \text { very small demand } o \text { demand } \rightarrow \text { price } \\
&=\left\{0.09 / x_{1}+0.16 / x_{2}+0.20 / x_{3}+0.36 / x_{4}+0.49 / x_{5}\right\} \\
& o\left\{0.3 / x_{1}+0.4 / x_{2}+0.45 / x_{3}+0.6 / x_{4}+0.7 / x_{5}\right\} \\
&=\left\{0.09 / x_{1}+0.16 / x_{2}+0.20 / x_{3}+0.36 / x_{4}+0.49 / x_{5}\right\}
\end{aligned}
$$

Proposed fuzzy reasoning is given by

$$
\begin{aligned}
& \text { very small demand } o \text { demand } \rightarrow \text { price } \\
&=\left\{0.09 / x_{1}+0.16 / x_{2}+0.20 / x_{3}+0.36 / x_{4}+0.49 / x_{5}\right\} \\
& o\left\{0.3 / x_{1}+0.4 / x_{2}+0.45 / x_{3}+0.6 / x_{4}+0.7 / x_{5}\right\} \\
&=\left\{0.09 / x_{1}+0.16 / x_{2}+0.20 / x_{3}+0.36 / x_{4}+0.49 / x_{5}\right\}
\end{aligned}
$$

Similarly the fuzzy quantifiers may be given as

$$
\text { more demand }=\left\{0.55 / x_{1}+0.63 / x_{2}+0.67 / x_{3}+0.77 / x_{4}+0.84 / x_{5}\right\}
$$

Zadeh [2] fuzzy reasoning is given by

$$
\begin{aligned}
& \text { very small demand } o \text { demand } \rightarrow \text { price } \\
&=\left\{0.55 / x_{1}+0.63 / x_{2}+0.67 / x_{3}+0.77 / x_{4}+0.84 / x_{5}\right\} \\
& o\left\{1.0 / x_{1}+1.0 / x_{2}+1.0 / x_{3}+1.0 / x_{4}+1.0 / x_{5}\right\} \\
&=\left\{0.55 / x_{1}+0.63 / x_{2}+0.67 / x_{3}+0.77 / x_{4}+0.84 / x_{5}\right\}
\end{aligned}
$$

Momdani [3] fuzzy reasoning is given by 


$$
\begin{aligned}
& \text { very small demand } o \text { demand } \rightarrow \text { price } \\
&=\left\{0.55 / x_{1}+0.63 / x_{2}+0.67 / x_{3}+0.77 / x_{4}+0.84 / x_{5}\right\} \\
& o\left\{0.3 / x_{1}+0.4 / x_{2}+0.45 / x_{3}+0.6 / x_{4}+0.7 / x_{5}\right\} \\
&=\left\{0.3 / x_{1}+0.4 / x_{2}+0.45 / x_{3}+0.6 / x_{4}+0.7 / x_{5}\right\}
\end{aligned}
$$

Proposed fuzzy reasoning is given by

$$
\begin{aligned}
& \text { very small demand } o \text { demand } \rightarrow \text { price } \\
&=\left\{0.55 / x_{1}+0.63 / x_{2}+0.67 / x_{3}+0.77 / x_{4}+0.84 / x_{5}\right\} \\
& o\left\{0.3 / x_{1}+0.4 / x_{2}+0.45 / x_{3}+0.6 / x_{4}+0.7 / x_{5}\right\} \\
&=\left\{0.3 / x_{1}+0.4 / x_{2}+0.45 / x_{3}+0.6 / x_{4}+0.7 / x_{5}\right\}
\end{aligned}
$$

\section{Generalized Fuzzy Data Mining}

The relational database is a Cartesian product of attributes and is represented as

$$
R=A_{1} \times A_{2} \times \cdots \times A_{n}
$$

or

$$
\begin{gathered}
t_{i}=\left(d_{i 1}, d_{i 2}, \cdots, d_{i i n}\right), d_{i j} \in A_{i} \\
R\left(A_{1}, A_{2}, \cdots, A_{n}\right)
\end{gathered}
$$

The fuzzy relational database in Table 1 may be defined for Attributes

$$
\begin{gathered}
R=\left\{t, \mu_{d}^{\mathrm{FCF}}(t)\right\} \\
\mu_{d}^{\mathrm{FCF}}(x)=\mu_{d}^{\text {belief }}(x)-\mu_{d}^{\text {disbelief }}(x) \\
\mu_{D}(r)=\mu_{d}\left(t_{1}\right)+\mu_{d}\left(t_{2}\right)+\cdots+\mu_{d}\left(t_{n}\right)
\end{gathered}
$$

Where "+" is union, $D$ is domain and $t_{i}$ are tupls.

$$
\begin{gathered}
1-C=1-\mu_{C}(x) \quad \text { Negation } \\
C V D=\max \left\{\mu_{C}(x) \cdot \mu_{D}(x)\right\} \quad \text { Disjunction } \\
C \Lambda D=\min \left\{\mu_{C}(x) \cdot \mu_{D}(x)\right\} \quad \text { Conjunction } \\
C \rightarrow D=\min \left\{1,1-\mu_{C}(x)+\mu_{D}(x)\right\} \quad \text { Implication } \\
C_{1} o C \rightarrow D=\min \left\{C_{1}, C \rightarrow D\right\} \quad \text { Composition }
\end{gathered}
$$

The fuzzy quantifiers "very" and "more" are given by

$$
\mu_{\text {very } d}(r)=\left\{\mu_{\text {very } d}(r)\right\}^{2}
$$

Table 1. Fuzzy relational database.

\begin{tabular}{ccc}
\hline & $d_{1}$ & $\mu$ \\
\hline$t_{1}$ & $a_{1}$ & $\mu_{d}\left(t_{1}\right)$ \\
$t_{2}$ & $a_{2}$ & $\mu_{d}\left(t_{2}\right)$ \\
$\cdot$ & $\cdot$ & $\cdot$ \\
$t_{n}$ & $a_{n}$ & $\mu_{d}\left(t_{n}\right)$ \\
\hline
\end{tabular}




$$
\begin{gathered}
\mu_{\text {more } d}(r)=\left\{\mu_{\text {more } d}(r)\right\}^{0.5} \\
\text { sales }=(0.5-0.1)=0.4 / 40+(0.6-0.1) \\
=0.5 / 50+(0.7-0.1)=0.6 / 60+(0.9-0.1) \\
=0.8 / 80+(1.0-0.1)=0.9 / 100
\end{gathered}
$$

It is shown in Table 2.

$$
\begin{aligned}
\text { price } & =(0.5-0.1)=0.4 / 40+(0.6-0.1) \\
& =0.5 / 50+(0.7-0.1)=0.6 / 60+(0.9-0.1) \\
& =0.8 / 80+(1.0-0)=1.0 / 100
\end{aligned}
$$

It is shown in Table 3.

1) Negation in Table 4.

2) Union in Table 5.

3) Intersection in Table 6.

4) Fuzzy Implication in Table 7.

Table 2. Fuzzy sales database.

\begin{tabular}{lcc}
\hline Cno & Iname & $\mu$ \\
\hline C101 & coffee & 0.8 \\
C101 & Milk & 0.6 \\
C103 & tea & 0.9 \\
C102 & milk & 0.5 \\
C101 & Sugar & 0.8 \\
C102 & coffee & 0.4 \\
\hline
\end{tabular}

Table 3. Fuzzy Price database.

\begin{tabular}{lcc}
\hline Cno & Iname & $\mu$ \\
\hline C101 & coffee & 1.0 \\
C101 & Milk & 0.5 \\
C103 & tea & 0.8 \\
C102 & milk & 0.8 \\
C101 & Sugar & 0.6 \\
C102 & coffee & 1.0
\end{tabular}

Table 4. The negation of price.

\begin{tabular}{ccc}
\hline Cno & Iname & $\mu$ \\
\hline C101 & coffee & 0.2 \\
C101 & Milk & 0.4 \\
C103 & tea & 0.1 \\
C102 & milk & 0.5 \\
C101 & Sugar & 0.2 \\
C102 & coffee & 0.6 \\
\hline
\end{tabular}


Table 5. The union of sales and price.

\begin{tabular}{ccc}
\hline Cno & Iname & $\mu$ \\
\hline C101 & coffee & 1.0 \\
C101 & Milk & 0.6 \\
C103 & tea & 0.8 \\
C102 & milk & 0.8 \\
C101 & Sugar & 0.8 \\
C102 & coffee & 1.0 \\
\hline
\end{tabular}

Table 6. The intersection of Sales or Price.

\begin{tabular}{ccc}
\hline Cno & Iname & $\mu$ \\
\hline C101 & coffee & 0.8 \\
C101 & Milk & 0.5 \\
C103 & tea & 0.8 \\
C102 & milk & 0.5 \\
C101 & Sugar & 0.6 \\
C102 & coffee & 0.4 \\
\hline
\end{tabular}

Table 7. Fuzzy Implication sales $\rightarrow$ price.

\begin{tabular}{ccccc}
\hline Cno & Iname & Zadeh & Mamdani & Proposed \\
C101 & coffee & 1.0 & 0.8 & 0.8 \\
C101 & Milk & 0.9 & 0.5 & 0.6 \\
C103 & tea & 0.9 & 0.8 & 0.9 \\
C102 & milk & 1.0 & 0.5 & 0.5 \\
C101 & Sugar & 0.8 & 0.6 & 0.8 \\
C102 & coffee & 1.0 & 0.4 & 0.4 \\
\hline
\end{tabular}

Table 8. Customers who purchased $>0.5$.

\begin{tabular}{cc}
\hline Cno & Frequency \\
\hline C101 & 2 \\
$\mathrm{C} 102$ & 1 \\
$\mathrm{C} 103$ & 1 \\
\hline
\end{tabular}

5) Fuzzy frequency in Table 8.

Fuzzy frequency in Table 9 may be defined as

$$
\text { Frequency }=0.2 / 1+0.2 / 3+0.35 / 3+0.45 / 4+0.45 / 5
$$

6) Fuzzy Association

The fuzzy functional dependency [8] FFD; $X \rightarrow Y$ or $Y$ is depending on $X$ is defined by 
if $E Q\left(t_{1}(X), t_{2}(X)\right)$ then $E Q\left(t_{1}(Y), t_{2}(Y)\right)$

if $F A\left(t_{1}(X), t_{2}(X)\right)$ then $F A\left(t_{1}(Y), t_{2}(Y)\right)=\min \left(t_{1}(Y), t_{2}(Y)\right)$

7) Fuzzy association in Table 10.

8) Fuzzy Clustering in Table 11.

Fuzzy sales database and Fuzzy Price database are shown in Table 12 and Table 13.

Table 9. Fuzzy frequency.

\begin{tabular}{lc}
\hline Cno & $\mu$ \\
\hline $\mathrm{C} 101$ & 0.3 \\
$\mathrm{C} 102$ & 0.2 \\
$\mathrm{C} 103$ & 0.2 \\
\hline
\end{tabular}

Table 10. Customers the items together purchased.

\begin{tabular}{ccc}
\hline Cno & Association & $\mu$ \\
\hline C101 & Coffee, Sugar & 0.6 \\
C102 & Milk, Coffee & 0.3 \\
\hline
\end{tabular}

Table 11. Clustering of items purchased $>0.9$.

\begin{tabular}{ccc}
\hline Cno & Iname & $\mu$ \\
\hline C101 & coffee & 0.8 \\
& Milk & 0.6 \\
& Sugar & 0.8 \\
C102 & milk & 0.5 \\
& coffee & 0.4 \\
\hline
\end{tabular}

Table 12. Fuzzy sales database.

\begin{tabular}{cccc}
\hline ino & Iname & Sales & $\mu$ \\
\hline I105 & Coffee & 80 & 0.7 \\
I107 & Milk & 60 & 0.6 \\
I104 & Tea & 100 & 0.8 \\
I108 & Sugar & 50 & 0.6 \\
\hline
\end{tabular}

Table 13. Fuzzy Price database.

\begin{tabular}{cccc}
\hline ino & Iname & price & $\mu$ \\
$\mathrm{I} 105$ & Coffee & 100 & 0.9 \\
$\mathrm{I} 107$ & Milk & 50 & 0.5 \\
$\mathrm{I} 104$ & Tea & 80 & 0.8 \\
$\mathrm{I} 108$ & Sugar & 60 & 0.6 \\
\hline
\end{tabular}




\section{Fuzzy Reasoning}

The fuzzy reasoning is drawing conclusions.

Consider the fuzzy reasoning:

If $x$ is $A$ then $y$ is $B$

$x$ is more $A$

$y$ is more $A$ o $(A \rightarrow B)$

If $x$ is sales then $y$ is price

is more sales

$y$ is more sales o (sales $\rightarrow$ price)

It is shown in Tables 14-17.

Table 14. Fuzzy sales.

\begin{tabular}{ccc}
\hline ino & Iname & sales \\
\hline I105 & Coffee & 0.7 \\
I107 & Milk & 0.6 \\
I104 & Tea & 0.8 \\
I108 & Sugar & 0.6 \\
\hline
\end{tabular}

Table 15. Fuzzy price.

\begin{tabular}{ccc}
\hline ino & Iname & price \\
\hline $\mathrm{I} 105$ & Coffee & 0.9 \\
$\mathrm{I} 107$ & Milk & 0.5 \\
$\mathrm{I} 104$ & Tea & 0.8 \\
$\mathrm{I} 108$ & Sugar & 0.6 \\
\hline
\end{tabular}

Table 16. More sales.

\begin{tabular}{ccc}
\hline ino & Iname & more sales \\
\hline I105 & Coffee & 0.83 \\
I107 & Milk & 0.77 \\
I104 & Tea & 0.89 \\
I108 & Sugar & 0.77
\end{tabular}

Table 17. Sales $\rightarrow$ price.

\begin{tabular}{ccccc}
\hline ino & Iname & Zadeh & Mamdani & proposed \\
\hline I105 & Coffee & 1.0 & 0.7 & 0.7 \\
I107 & Milk & 0.9 & 0.5 & 0.6 \\
I104 & Tea & 1.0 & 0.8 & 0.8 \\
I108 & Sugar & 1.0 & 0.6 & 0.6 \\
\hline
\end{tabular}


Table 18. Fuzzy reasoning for price.

\begin{tabular}{ccccc}
\hline ino & Iname & Zadeh & Mamdani & proposed \\
\hline I105 & Coffee & 0.83 & 0.7 & 0.7 \\
I107 & Milk & 0.77 & 0.5 & 0.6 \\
I104 & Tea & 0.89 & 0.8 & 0.8 \\
I108 & Sugar & 0.77 & 0.6 & 0.6 \\
\hline
\end{tabular}

Zadeh fuzzy reasoning is given by

$y$ is more sales o (sales $\rightarrow$ price)

$=\min \{$ more sales, $\min (1,1$-sales + price $)\}$

Mamdani fuzzy reasoning is given by

$y$ is more sales o (sales $\rightarrow$ price)

$=\min \{$ more sales, $\min ($ sales, price) $\}$

Proposed fuzzy reasoning is given by

yis more sales o (sales $\rightarrow$ price)

$=\min \{$ more sales, sales $)\}$

It is shown in Table 18.

Consider the nested fuzzy conditional inference for business intelligence:

If Demand then if Supply then increase price.

which is equivalent to:

If Demand and Supply then increase price.

The nested conditional fuzzy inference may be applied in fuzzy data mining similarly.

\section{Acknowledgements}

The author would like thank Editor-in-Chief, JSEA for accepting this paper.

\section{References}

[1] Zadeh, L.A. (1965) Fuzzy Sets. In Control, 8, 338-353. https://doi.org/10.1016/S0019-9958(65)90241-X

[2] Zadeh, L.A. (1975) Calculus of Fuzzy Restrictions. In: Zadeh, L.A., King-Sun, F.U., Tanaka, K. and Shimura, M., Eds., Fuzzy Sets and Their Applications to Cognitive and Decision Processes, Academic Press, New York, 1-40. https://doi.org/10.1016/B978-0-12-775260-0.50006-2

[3] Mamdani, E.H. and Assilian, S. (1975) An Experiment in Linguistic Synthesis with a Fuzzy Logic Control. International Journal of Man-Machine Studies, 7, 1-13. https://doi.org/10.1016/S0020-7373(75)80002-2

[4] Takagi, T. and Sugeno, M. (1985) Fuzzy Identification of Systems and Its Application to Modelling and Control. Systems, Man and Cybernetics, 1, 194-207.

[5] Reddy, P.V.S. (2015) Fuzzy Data Mining and Web Intelligence. International Conference on iFuuzy 2015, Taiwan, 18-20 November 2015, 74-79.

[6] Buchanan, B.G. and Shortliffe, E.H. (1984) Rule Based Expert Systems: The MYCIN Experiments of the Stanford Heuristic Programming Project. Addison-Wesley, Reading, MA. 
[7] Reddy, P.V.S. (1993) Fuzzy Conditional Inference for Medical Diagnosis. Proceedings of Second International Conference on Fuzzy Theory and Technology, Summary FT\&T 1993, 193-195.

[8] Reddy, P.V.S. (2016) Fuzzy Map Reducing Algorithm for BIG DATA. iFuzzy 2016, IEEE Explore, 4-8. 